$$
\begin{aligned}
& 34 N C^{\circ} \cdot 9 \\
& \text { CONF. } 9605185 .-2
\end{aligned}
$$

\title{
GROUND PENETRATING RADAR ENABLED BY HIGH GAIN GaAs PHOTOCONDUCTIVE SEMICONDUCTOR SWITCHES
}

\author{
G. M. Loubriel, M. T. Buttram, J. F. Aurand, and F. J. Zutavern \\ High Power Electromagnetics Department \\ Sandia National Laboratories, P. O. Box 5800, MS 1153, \\ Albuquerque, NM 87185-1153, (505) 845-7096
}

\begin{abstract}
The ability of high gain GaAs Photoconductive Semiconductor switches (PCSS) to deliver fast risetime, low jitter pulses when triggered with small laser diode arrays makes them suitable for their use in ultrawide bandwidth (UWB), impulse transmitters. This paper will summarize the state-of-the-art in high gain GaAs switches and discuss how GaAs switches are being implemented in a transmitter for detection of underground structures. The advantage of this type of semiconductor switch is demonstrated operation at high voltages $(100 \mathrm{kV})$ and repetition rates $(1 \mathrm{kHz})$ with the potential for much higher repetition rates. The latter would increase the demonstrated average powers of $100 \mathrm{~W}$ to $1 \mathrm{~kW}$ and higher. We will also present an analysis of the effectiveness of different pulser geometries that result in transmitted pulses with varying frequency content. To this end, we have developed a simple model that includes transmit and receive antenna response, attenuation and dispersion of the electromagnetic impulses by the soil, and target cross sections.
\end{abstract}

\section{INTRODUCTION (STATE-OF-THE-ART OF HIGH GAIN GaAs PCSS)}

This research has focused on optically triggered, high gain GaAs switches for impulse sources for ultrawide bandwidth (UWB) transmitters. The practical significance of this high gain switching mode is that the switches can be activated with very low energy optical triggers, allowing for compact sources. ${ }^{1}$ For example, we have shown ${ }^{2}$ that a $90 \mathrm{~nJ}$ optical pulse has triggered switches that have delivered $48 \mathrm{MW}$ in a 30-50 $\Omega$ system, and previously we have switched $6 \mathrm{MW}$ for $\sim 100 \mathrm{~ns}$ in a $0.25 \Omega$ system. ${ }^{3}$ The GaAs switches used in this experiment are lateral switches: they have two contacts on one side of a wafer separated by an insulating region of intrinsic material. At electric fields below $4 \mathrm{kV} / \mathrm{cm}$, the 


\section{DISCLAIMER}

This report was prepared as an account of work sponsored by an agency of the United States Government. Neither the United States Government nor any agency thereof, nor any of their employees, makes any warranty, express or implied, or assumes any legal liability or responsibility for the accuracy, completeness, or usefulness of any information, apparatus, product, or process disclosed, or represents that its use would not infringe privately owned rights. Reference herein to any specific commercial product, process, or service by trade name, trademark, manufacturer, or otherwise does not necessarily constitute or imply its endorsement, recommendation, or favoring by the United States Government or any agency thereof. The views and opinions of authors expressed herein do not necessarily state or reflect those of the United States Government or any agency thereof. 


\section{DISCLAIMER}

Portions of this document may be illegible in electronic image products. Images are produced from the best available original document. 
GaAs switches are activated by the creation of, at most, one electron hole pair per photon absorbed. This linear mode demands high laser power, and after the light is extinguished, the carrier density decays in 1-10 ns. At higher electric fields these switches behave very differently. The high field induces carrier multiplication so that the amount of light required is reduced by as much as five orders of magnitude. ${ }^{1,2}$ This high gain mode is characterized

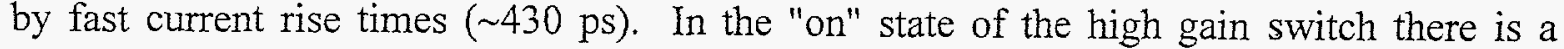
characteristic, constant field across the switch called the lock-on field. The switch current is circuit-limited provided the circuit maintains the lock-on field. ${ }^{3}$ As the field increases, the switch risetime decreases and the trigger energy is reduced. ${ }^{3}$ The PCSS are being tested for use in applications such as: UWB transmitters, firing sets for munitions, electro-optic modulators, current interrupters, active optical sensors, and pulsed power applications such as MV accelerators that operate at high repetition rates. Each of these applications imposes a different set of requirements on switch properties. Table I shows the best results obtained with the switches for these applications. The results are not all simultaneous. The work of many others has been presented at various conferences. ${ }^{4}$

Table 1. Results of tests with high gain GaAs switches. The first column is the best results obtained in various, independent tests. The second column are the results from a single system which can be used to produce ultra wideband pulses.

\begin{tabular}{|l|c|c|}
\hline \multicolumn{1}{|c|}{$\begin{array}{c}\text { Table I } \\
\text { Parameter }\end{array}$} & $\begin{array}{c}\text { Best } \\
\text { Individual } \\
\text { Results }\end{array}$ & $\begin{array}{c}\text { Simultaneous } \\
\text { Results } \\
\text { (see next section) }\end{array}$ \\
\hline Switch Voltage (kV) & 155 & 100 \\
\hline Switch Current (kA) & 7.0 & 1.26 \\
\hline Peak Power (MW) & 120 & 48 \\
\hline Rise time (ps) & 430 & 430 \\
\hline R-M-S jitter (ps) & 150 & 150 \\
\hline Optical Trigger Energy (nJ) & 90 & 180 \\
\hline Repetition Rate (Hz) & 1,000 & 1,000 \\
\hline Electric Field (kV/cm) & 100 & 67 \\
\hline Device Lifetime (\# pulses) & $6 \times 10^{6}$ & $5 \times 10^{4},($ at $77 \mathrm{kV})$ \\
\hline
\end{tabular}

* Not all the results are simultaneous.

\section{INITIAL IMPULSE SYSTEM}

The feasibility of using GaAs switches to create voltage pulses suitable for driving UWB antennas has been previously demonstrated. ${ }^{2}$ In that study we charged a nominally $1.0 \mathrm{~ns}$ long, $47 \Omega$, parallel plate transmission line to voltages of about $100 \mathrm{kV}$. This line was discharged with either one or two switches into a $30 \Omega$ load. The circuit is shown in Figure 1. We measured the voltage on the transmission line and the current through the load. The voltage on the line rose to a peak value $(100 \mathrm{kV}$ in most cases, although voltages of $110 \mathrm{kV}$ were also used) with a risetime of $210 \mathrm{~ns}$. At peak voltage the laser diode arrays activated the switch and the line voltage dropped. If only switch one was triggered, the resulting load voltage was a monopulse. If both switches were triggered simultaneously the load current was a monocycle (bipolar pulse). This system operated in bursts of up to 5 
pulses at a repetition rate of $1 \mathrm{kHz}$. The switches were fabricated from undoped GaAs with $\mathrm{Ni}-\mathrm{Ge}-\mathrm{Au}-\mathrm{Ni}$-Au metallization. Their insulating region separating the two contacts was 1.5 $\mathrm{cm}$, the total contact width was $7.6 \mathrm{~cm}$. Because of the high electric fields the switches were immersed in a dielectric liquid (Fluorinert 8 ). To avoid corona and breakdown, the charged transmission line was in $\mathrm{SF}_{6}$ gas. The laser diode arrays (with most of their electronics) are about 2 " by 2 " in size and were used in a configuration that allowed triggering the switches with as little as $90 \mathrm{~nJ}$ of energy.

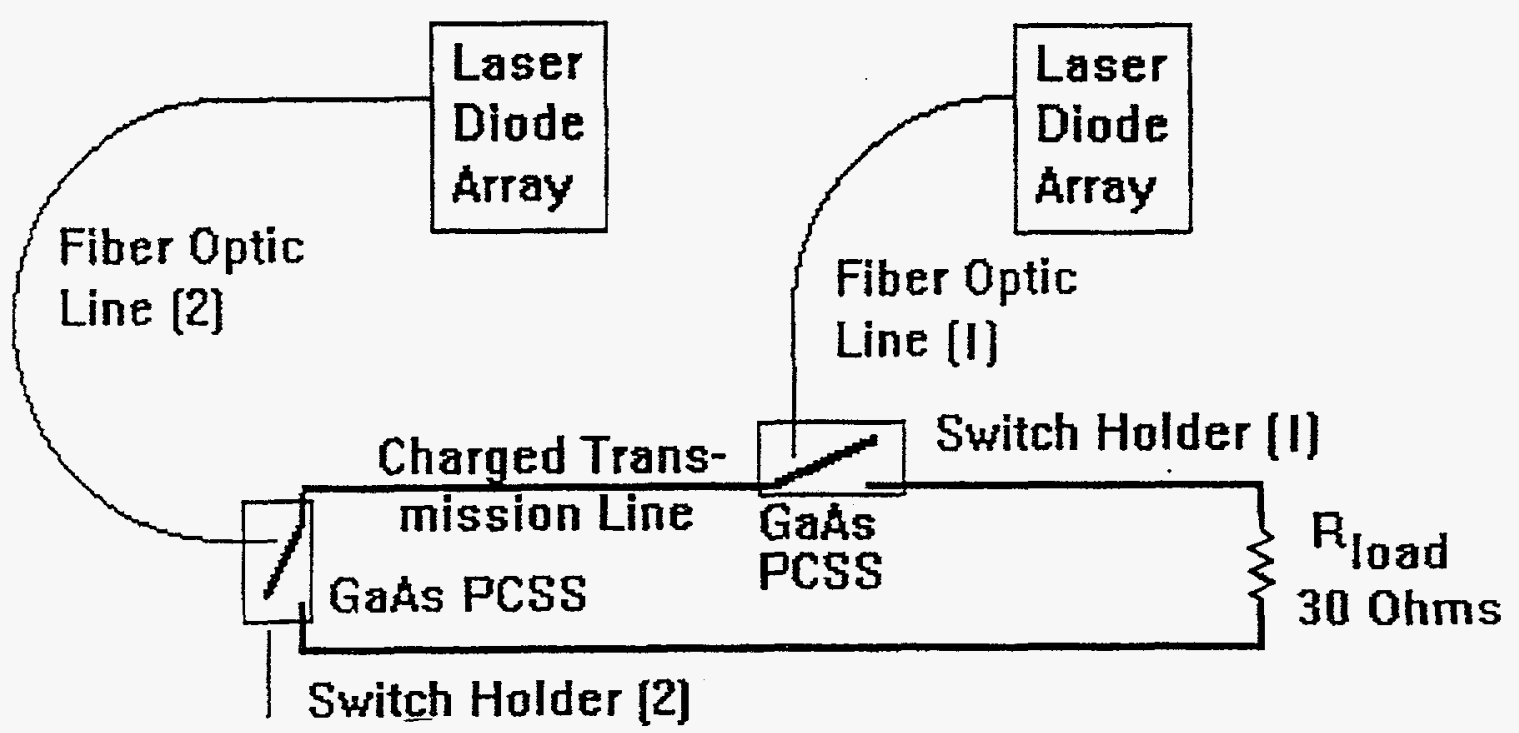

Figure 1. A short (1 ns), $47 \Omega$ transmission line (the charge line) was charged to high voltage at a burst repetition rate of $1 \mathrm{kHz}$. Two switches were used on either side of the line to discharge the line into a $30 \Omega$ load.

In one set of tests both laser diode arrays were used to activate switch one (in a configuration not shown in the figure) and obtain a monopulse. The highest current measured with this system is shown in Figure 2. The width of the current pulse and its peak value depend on the time delay between when the two laser diodes are triggered. When both diodes are triggered to produce simultaneous current pulses, the current is largest and the current pulse width is smallest. The highest current was $1.26 \mathrm{kA}$ with a rise time of $430 \mathrm{ps}$ and a pulse width of $1.4 \mathrm{~ns}$. The peak power is $48 \mathrm{MW}$. With one laser diode activating one switch the current is about 1.0 to $1.1 \mathrm{kA}$ with a rise time of about $770 \mathrm{ps}$ and a pulse width of $1.7-1.9 \mathrm{~ns}$.

The second set of tests utilized both laser diodes, each triggering one switch, to produce a monocycle. Figure 3 shows the current waveform. In theory, with ideal switching, the monocycle should be composed of two monopulses of opposite polarity each with half the pulse width. Thus, we expect a monocycle composed of a negative and a positive pulse, each with a width of $0.9 \mathrm{~ns}$. What we observe is a width of $1.0 \mathrm{~ns}$ for the negative pulse and $1.3 \mathrm{~ns}$ for the positive pulse. The reason for this is a timing error of about 200 ps. The minimum width should occur when both switches are triggered simultaneously. It is very important to trigger both switches at the same time to obtain full voltage and to obtain the proper waveform. In these tests, the switch jitter did not allow us to always reproduce the monocycle. As will be seen in the next sections, this monocycle is 
more effective than the monopulse for ground penetration. To reduce jitter it will be necessary to increase the laser energy. Fortunately, the laser diode array can be run, with electronics of the same size, at up to $1 \mu \mathrm{J}$ of energy. At this energy we expect the jitter to be sufficiently small to allow for effective switching.

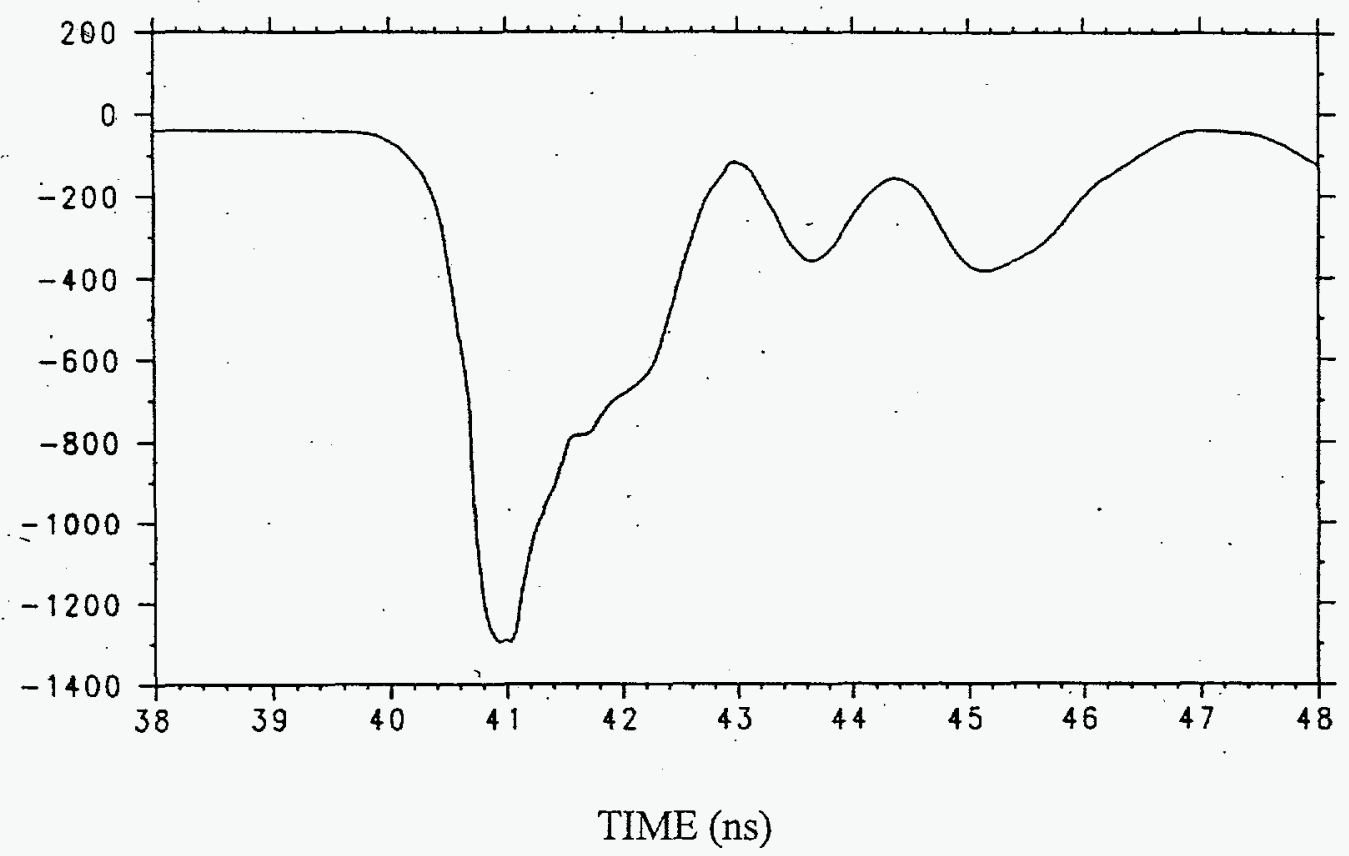

Figure 2. The current through the $30 \Omega$ load when both laser diodes illuminate one switch: 1.26 kA peak (48 MW), $430 \mathrm{ps}$ rise, 1.4 ns wide.

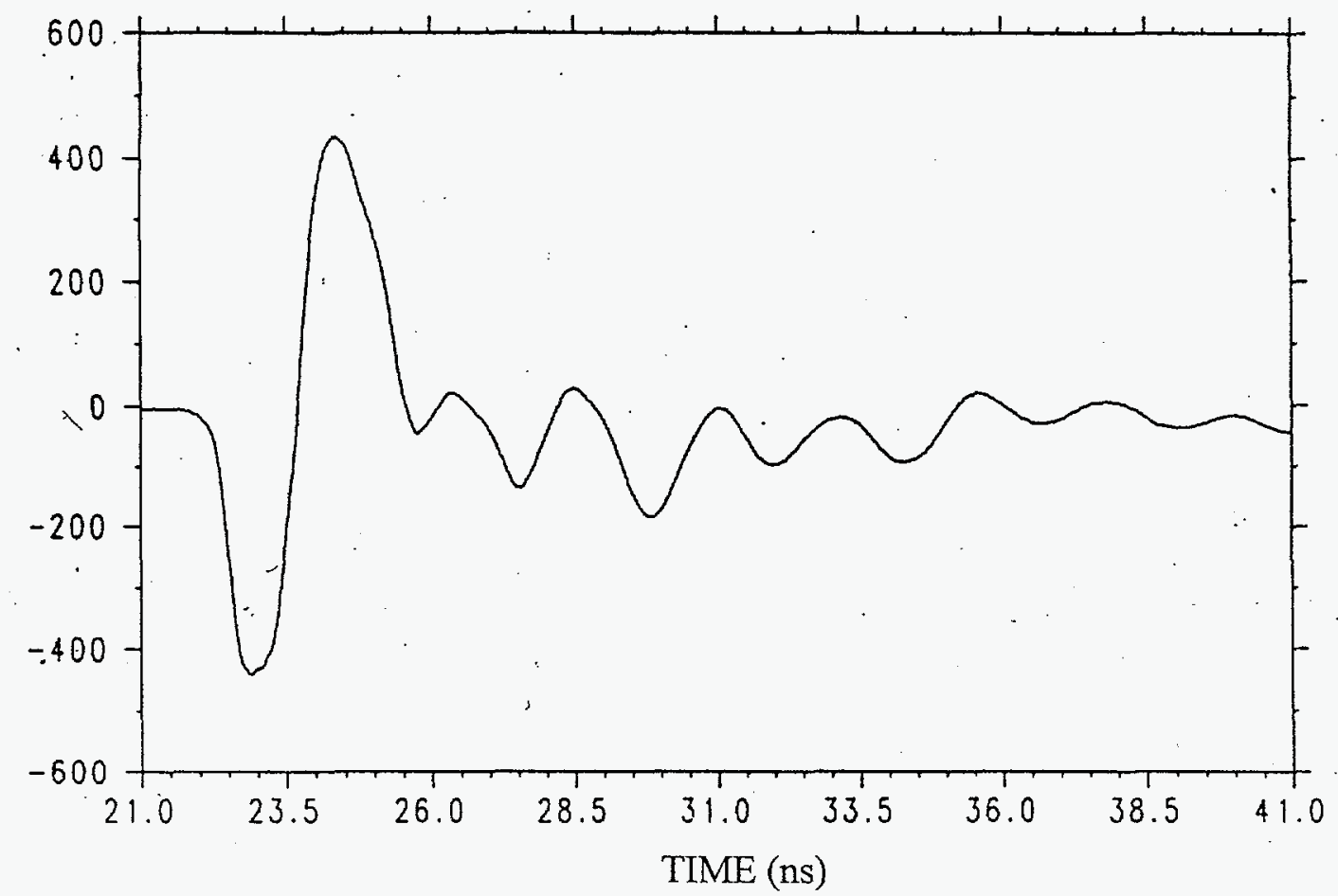

Figure 3. The current (in Amps) through the $30 \Omega$ load when each of the two laser diodes is used to trigger one switch. 


\section{MODEL OF RADAR SYSTEM}

To analyze the relative merits of different waveforms with varying frequency content we have developed a simple model that includes transmit and receive antenna response, attenuation and dispersion of the electromagnetic impulses by the soil, transmission at the air/soil boundary (upon entering and exiting), and target cross sections. The target that we will choose is a metallic, square plate $(10 \mathrm{~m}$ by $10 \mathrm{~m})$ buried at a depth $\mathrm{D}(10 \mathrm{~m}$ in this study). To examine the radar equation for a buried object, we use the simple radar equation for the frequency dependent amplitude of the transfer function [radar-to-target-to-receiver]. The beam is assumed to be normal to the ground which is flat and featureless. Figure 4 shows two different voltage waveforms (input to antenna): a monopulse and a monocycle (a bipolar pulse). The formulas used to calculate these waveforms are either a Gaussian (sigma $=0.8 \mathrm{~ns}$ ) centered at $5 \mathrm{~ns}$ or the derivative of a Gaussian. Both were normalized to peak amplitude of 1 (as shown). These waveforms were meant to mimic the results obtained with the previous impulse system. Figure 5 shows the frequency spectrum of both of these waveforms. The monopulse, due to its non-zero integral, has peak frequency content at 0.0 $\mathrm{Hz}$ (dc). Most of its energy content is from $0.0 \mathrm{~Hz}$ to about $200 \mathrm{MHz}$. The monocycle, on the other hand, has no frequency content at $0.0 \mathrm{~Hz}$ and peaks at $200 \mathrm{MHz}$. Most of its energy content is from $100 \mathrm{MHz}$ to $350 \mathrm{MHz}$.
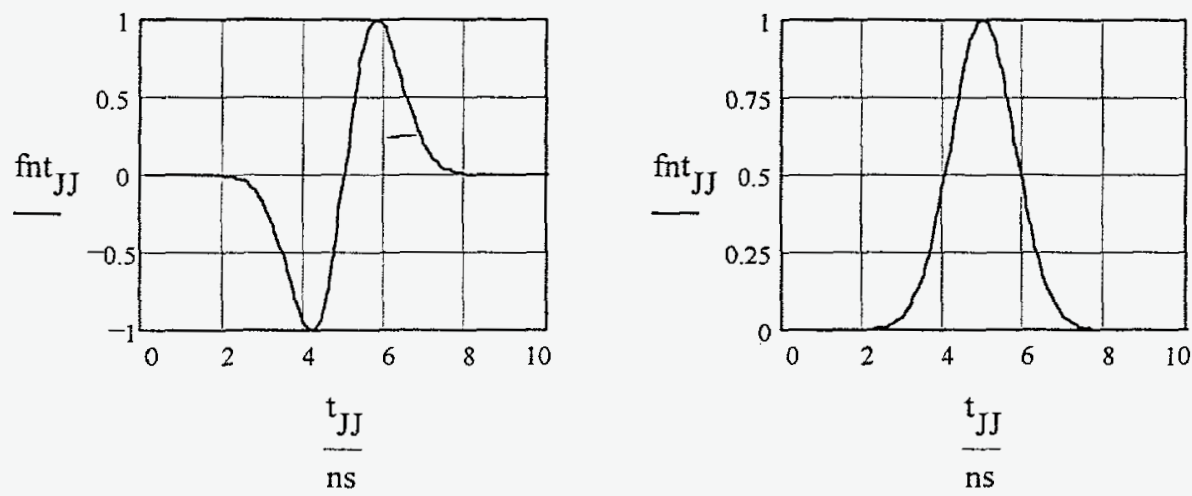

Figure 4. Voltage waveforms used in this study. On the left is a monocyle, on the right is a monopulse.
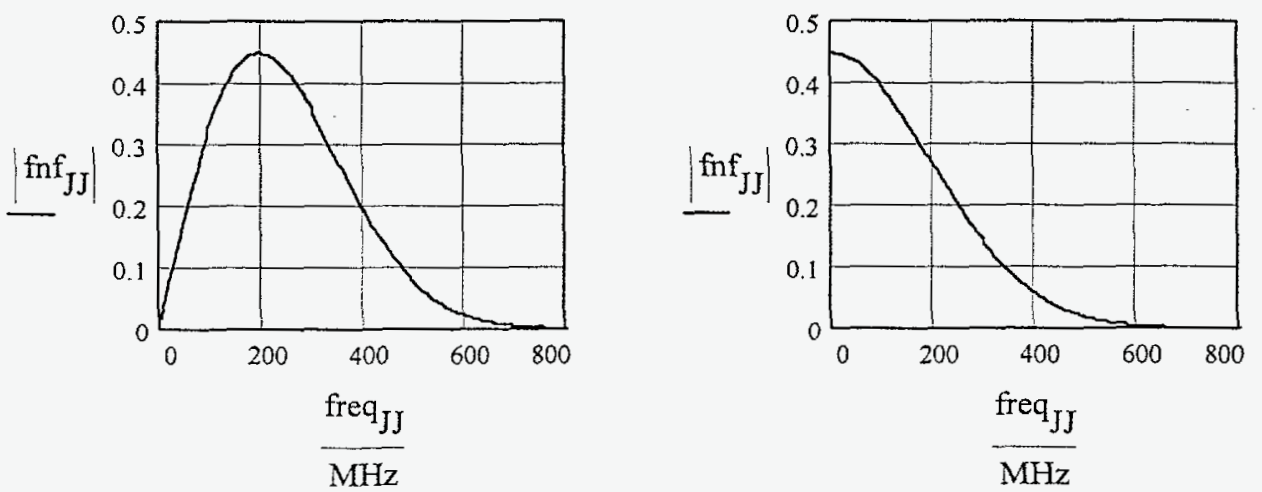

Figure 5. Frequency spectrum of the voltage waveforms (left: monocycle, right: monopulse). 

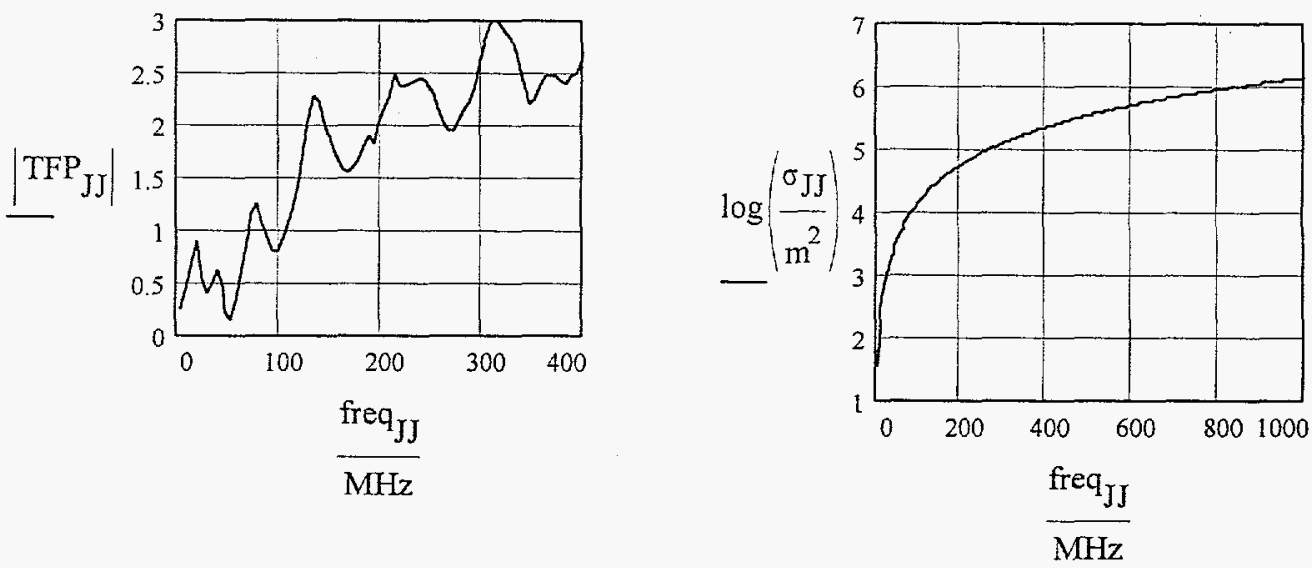

Figure 6. Antenna transfer function (left) and the cross section of a flat metal plate with dimensions of $10 \mathrm{~m}$ by $10 \mathrm{~m}$..

An existing antenna which may be used for this work is a large TEM horn with flared aperture plates and a high-voltage inline coaxial 'zipper' balun (the 'adapter' in reference 5) as the input section. It has a transfer function whose magnitude is shown in figure 6 . This was developed by measuring two time domain waveforms. One was a bipolar (monocycle) voltage pulse created by a custom pulse generator with a $+/-100 \mathrm{~V}$ amplitude, and primary spectral content from 50 to $400 \mathrm{MHz}$. The other was the main radiated E-field, at a range of $8.0 \mathrm{~m}$. The transfer function was then formed by the complex ratio of the discrete Fourier transform of the radiated field divided by the transform of the input excitation voltage. The cross section (in Air) of the target is also shown in figure 6 . Because the antenna transfer function and the target cross section are larger at higher frequencies, the monopulse waveforms will not radiate as efficiently as the monocycle. It is tempting to use waveforms that have very high frequency components. On the other hand, the attenuation by the soil is larger at higher frequencies. Figure 7 shows attenuation for two different types of soil: dry sand and San Antonio Clay Loam with a water content of 5\%. The soil was modelled using the parameters in reference 6 .
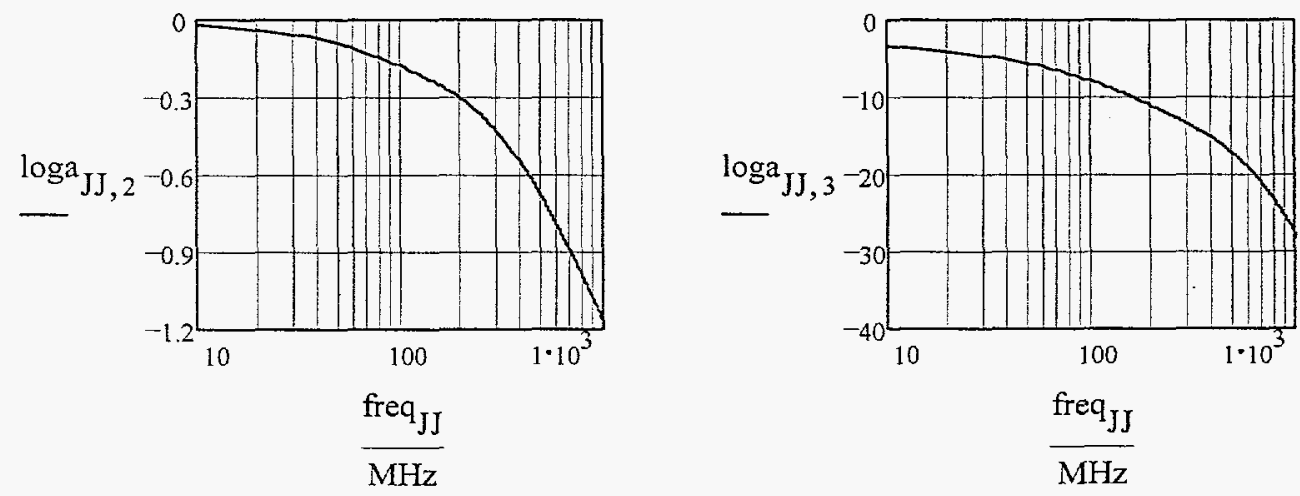

Figure 7. The $\log$ of the attenuation versus frequency for a penetration depth of $10 \mathrm{~m}$ for dry sand (left) and San Antonio clay loam, 5\% water (right). 
Using this information we can predict the receive waveform. Figures 8 and 9 show different receive electric field waveforms at the transmit site for a monocycle and monopulse voltage pulse. Figure 8 shows the return from penetration through $10 \mathrm{~m}$ of air and $10 \mathrm{~m}$ of soil. Note that the waveforms are similar to the derivative of the initial voltage pulse. Figure 9 shows the same type of results but with San Antonio clay loam with 5\% water content. The receive functions show two major effects. First, a large attenuation of about $10^{5}$ in intensity. Second, that the temporal extent of the pulse is now about $15 \mathrm{~ns}$. The pulse is expanded because the high frequencies are preferentially attenuated and the various frequency components are propagating through the soil at different speeds.
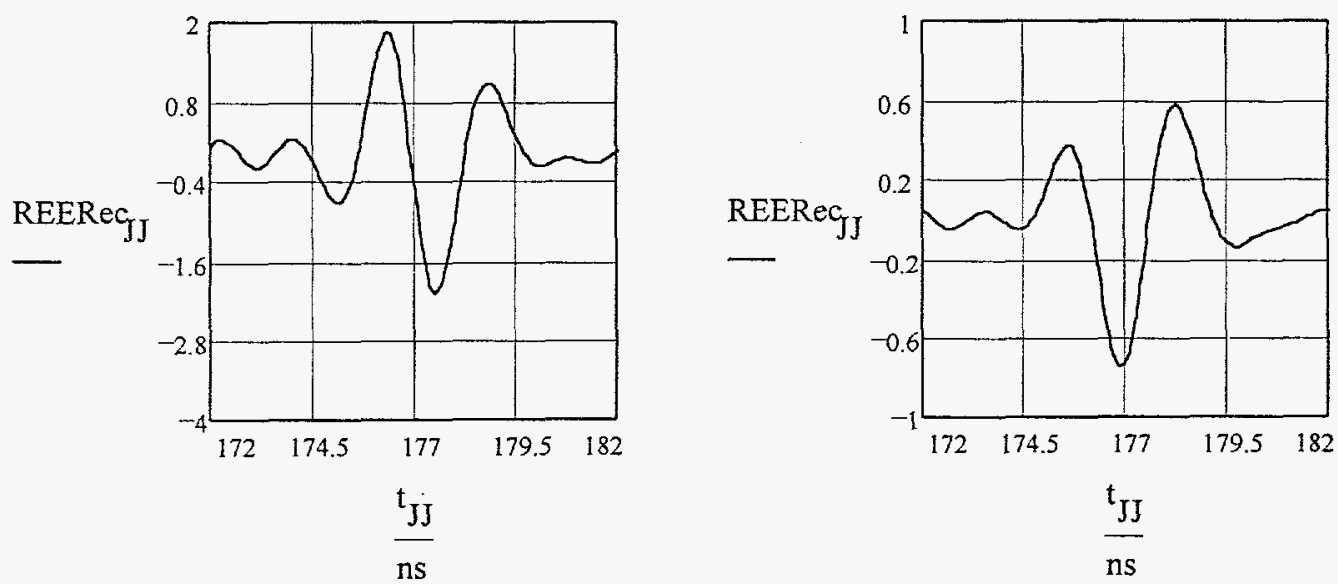

Figure 8. The electric field at the transmit site after transmission through the soil (dry sand) for the monocycle (left) and monopulse (right) waveforms.
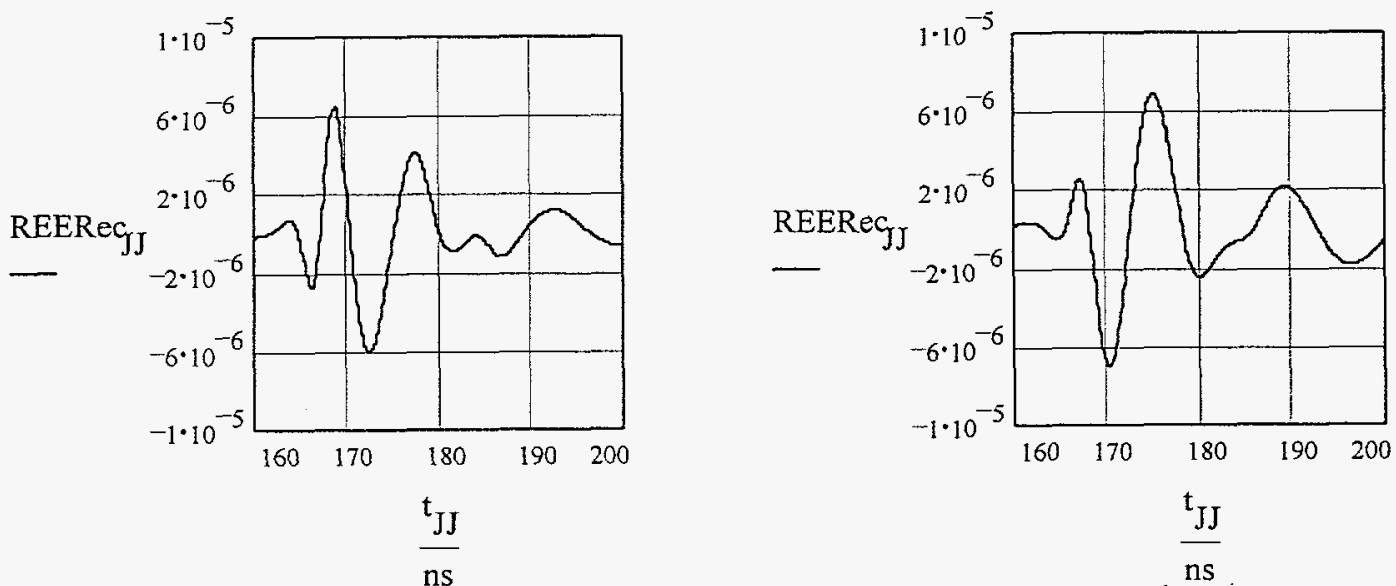

Figure 9. The electric field at the transmit site after transmission through the soil (San Antonio clay loam, $5 \%$ water) for the monocycle (left) and monopulse (right) waveforms.

\section{CONCLUSION}

We have developed a model that shows both the monocycle and monopulse waveforms should result in measurable penetration through different soils for the detection of large, deeply buried metal plates. There is little difference in the receive pulse amplitudes 
for these waveforms. That is surprising because the spectrum of the monopulse waveform has most of its energy at frequencies that are not transmitted by the antenna. This effect was cancelled by the attenuation of the soil. From a practical standpoint the production of a monopulse voltage waveform is much simpler than the monocycle and, thus, based solely on this result it may lead to the use of that type of waveform. Unfortunately, the monopulse may result in late time ringing of the antenna, since the energy that is not radiated stays trapped in the transmitter and may be radiated at later times. For this reason we will test both waveforms in future experiments to determine the transmitter efficiency and ringing.

The ultimate goal of the radar model is to assess different transmitter technologies for their effectiveness in detecting large, deeply buried structures. In particular, we need to know the average transmit power required for a given transmitter and target (of given size and depth). At this point in time, we know that we can produce $100 \mathrm{~W}$ average power, high peak power (48 MW) impulses in using laser diode triggered PCSS operated in the high gain mode in a configuration that allows for detection of large underground structures. The system needs to be optimized to allow for the highest possible average power, thus repetition rate is very important. The initial system was operated at a burst repetition rate of $1 \mathrm{kHz}$ but the switches can be operated at much higher repetition rates and thus average powers of $1 \mathrm{~kW}$ could be used, if needed.

\section{ACKNOWLEDGMENT}

The authors want to thank W, D. Helgeson, D. J. Brown, M. W. O'Malley, B. Brock, A. G. Baca, H. J. Hjalmarson, T. A. Plut, and C. H. Sifford for their help. This work was supported by the United States Department of Energy under contract DE-AC04-94AL85000.

\section{REFERENCES}

1. G. M. Loubriel, M. W. O'Malley, and F. J. Zutavern, "Toward Pulsed Power Uses for Photoconductive Semiconductor Switches: Closing Switches," Proc. 6th IEEE Pulsed Power Conference, P. J. Turchi and B. H. Bernstein, eds., Arlington, VA, 1987, p. 145.

2. G. M. Loubriel, F. J. Zutavern, M. W. O'Malley, and W. D. Helgeson, "High Gain GaAs Photoconductive Semiconductor Switches for Impulse Sources," Proc. of SPIE Optically Activated Switching Conference IV, SPIE Proc. Series Vol. 2343, pp. 180186, W. R. Donaldson, ed., Boston, MA, October 31-November 4, 1994.

3. F. J. Zutavern and G. M. Loubriel, "High Voltage Lateral Switches from Si or GaAs," High-Power Optically Activated Solid-State Switches, A. Rosen and F. J. Zutavern, Eds., Artech House, Boston, 1993, p. 245.

4. See Proceedings from: 6-8th IEEE Pulsed Power Conf., 1987, 1989, 1991; 18-20th IEEE

Power Modulator Symposium, 1988, 1990, 1992; SPIE Optically Activated Switching I-III, (vol. 1378, 1632, 1873), 1990, 1992, 1993; and IEEE Trans. Elec. Devices, (vol. 37, 38), 1990, 1992.

5. R. S. Clark, L. F. Rinehart, M. T. Buttram, and J. F. Aurand, "An overview of Sandia National Laboratories' Plasma Switched, GigaWatt, Ultra-Wideband ImpulseTransmitter Program," Ultra-Wideband, Short Pulse Electromagnetics, L. Bertoni, L. Carin, and L. Felsen, eds., Plenum Press, New York, 1993, pp. 93- 98.

6. B. C. Brock and W. E. Patitz, "Optimum Frequency for Subsurface-Imaging Synthetic Aperture Radar," Sandia National Laboratories' report SAND93-0815 and B. C. Brock and K. W. Sorensen, "Electromagnetic Scattering from Buried Objects," report SAND94-2361. 


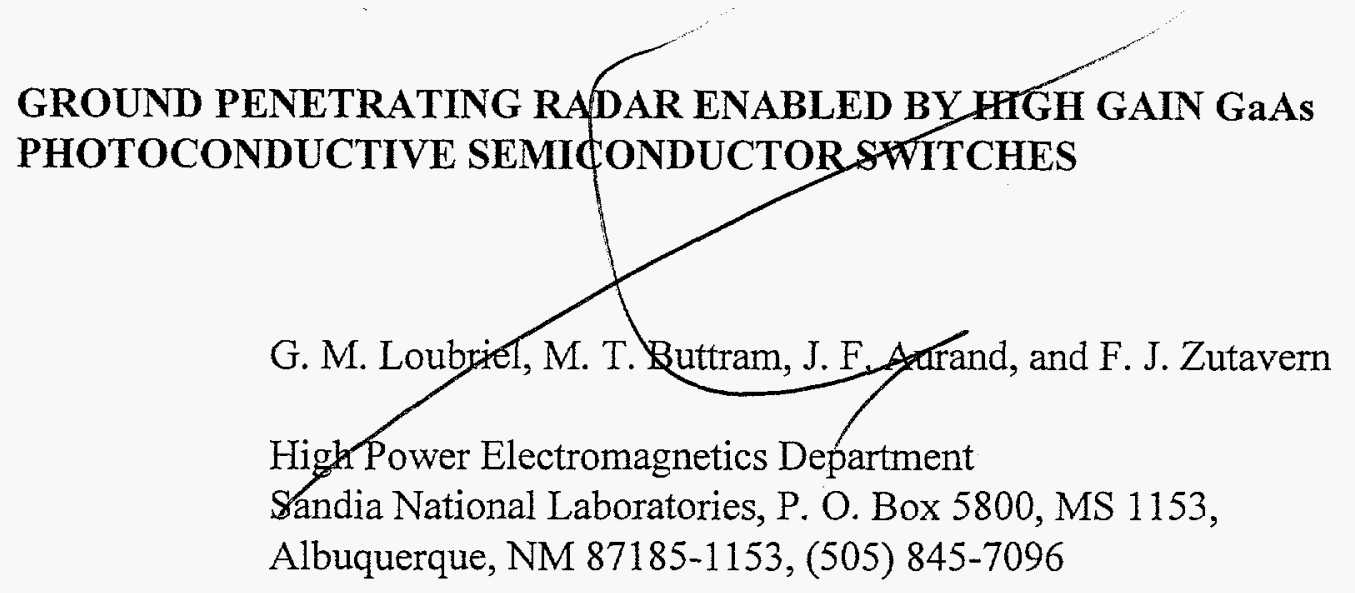

ABSTRACT

The ability of high gain GaAs Photoconductive Semiconductor switches (PCSS) to deliver fast risetime, low jitter pulses when triggered with small laser diode arrays makes them suitable for their use in ultrawide bandwidth (UWB), impulse transmitters. This paper will summarize the state-of-the-art in high gain GaAs switches and discuss how GaAs switches are being implemented in a transmitter for detection of underground structures. The advantage of this type of semiconductor switch is demonstrated operation at high voltages $(100 \mathrm{kV})$ and repetition rates $(1 \mathrm{kHz})$ with the potential for much higher repetition rates. The latter would increase the demonstrated average powers of $100 \mathrm{~W}$ to $1 \mathrm{~kW}$ and higher. We will also present an analysis of the effectiveness of different pulser geometries that result in transmitted pulses with varying frequency content. To this end, we have developed a simple model that includes transmit and receive antenna response, attenuation and dispersion of the electromagnetic impulses by the soil, and target cross sections.

\section{INTRODUCTION (STATE-OF-THE-ART OF HIGH GAIN GaAs PCSS)}

This research has foctused on optically triggered, high gain GaAs switches for impulse sources for ultrawide bandwidth (\&UWB) transmitters. The practical significance of this high gain switching mode is that the switches can be activated with very low energy optical triggers, allowing for compact sources. For example, we have shown ${ }^{2}$ that a $90 \mathrm{~nJ}$ optical pulse has triggered switches that have delivered 48 MU in a 30-50 $\Omega$ system, and previously we have switched $6 \mathrm{WW}$ for 100 ns in a $0.25 \Omega$ system. ${ }^{3}$ The GaAs switches used in this experiment are lateral switches: the have two contacts on one side of a wafer separated by an insulating region of intrinsic material. At electric fields below $4 \mathrm{kV} / \mathrm{cm}$, the 


\title{
GROUND PENETRATING RADAR ENABLED BY HIGH GAIN GaAs PHOTOCONDUCTIVE SEMICONDUCTOR SWITCHES
}

\author{
G. M. Loubriel, M. T. Buttram, J. F. Aurand, and F. J. Zutavern \\ High Power Electromagnetics Department \\ Sandia National Laboratories, P. O. Box 5800, MS 1153, \\ Albuquerque, NM 87185-1153, (505) 845-7096
}

\section{ABSTRACT}

The ability of high gain GaAs Photoconductive Semiconductor switches (PCSS) to deliver fast risetime, low jitter pulses when triggered with small laser diode arrays makes them suitable for their use in ultrawide bandwidth (UWB), impulse transmitters. This paper will summarize the state-of-the-art in high gain GaAs switches and discuss how GaAs switches are being implemented in a transmitter for detection of underground structures. The advantage of this type of semiconductor switch is demonstrated operation at high voltages $(100 \mathrm{kV})$ and repetition rates $(1 \mathrm{kHz})$ with the potential for much higher repetition rates. The latter would increase the demonstrated average powers of $100 \mathrm{~W}$ to $1 \mathrm{~kW}$ and higher. We will also present an analysis of the effectiveness of different pulser geometries that result in transmitted pulses with varying frequency content. To this end, we have developed a simple model that includes transmit and receive antenna response, attenuation and dispersion of the electromagnetic impulses by the soil, and target cross sections.

\section{INTRODUCTION (STATE-OF-THE-ART OF HIGH GAIN GaAs PCSS)}

This research has focused on optically triggered, high gain GaAs switches for impulse sources for ultrawide bandwidth (UWB) transmitters. The practical significance of this high gain switching mode is that the switches can be activated with very low energy optical triggers, allowing for compact sources. ${ }^{1}$ For example, we have shown ${ }^{2}$ that a $90 \mathrm{~nJ}$ optical pulse has triggered switches that have delivered $48 \mathrm{MW}$ in a 30-50 $\Omega$ system, and previously we have switched $6 \mathrm{MW}$ for $\sim 100 \mathrm{~ns}$ in a $0.25 \Omega$ system. ${ }^{3}$ The GaAs switches used in this experiment are lateral switches: they have two contacts on one side of a wafer separated by an insulating region of intrinsic material. At electric fields below $4 \mathrm{kV} / \mathrm{cm}$, the 